\title{
Growth factors acting via endothelial cell-specific receptor tyrosine kinases: VEGFs, Angiopoietins, and ephrins in vascular development
}

\author{
Nicholas W. Gale ${ }^{1}$ and George D. Yancopoulos \\ Regeneron Pharmaceuticals, Inc., Tarrytown, New York 10591-6707 USA
}

The term 'vasculogenesis' refers to the earliest stages of vascular development, during which vascular endothelial cell precursors undergo differentiation, expansion, and coalescence to form a network of primitive tubules (Risau 1997). This initial lattice, consisting purely of endothelial cells that have formed rather homogenously sized interconnected vessels, has been referred to as the primary capillary plexus. The primary plexus is then remodeled by a process referred to as angiogenesis (Risau 1997), which involves the sprouting, branching, and differential growth of blood vessels to form the more mature appearing vascular patterns seen in the adult organism. This latter phase of vascular development also involves the sprouting and penetration of vessels into previously avascular regions of the embryo, and also the differential recruitment of associated supporting cells, such as smooth muscle cells and pericytes, as well as fibroblasts, to different segments of the vasculature (Folkman and D'Amore 1996; Lindahl et al. 1997). The adult vascular network is comprised of large arteries, internally lined by endothelial cells and well ensheathed by smooth muscle cells, that progressively branch into smaller and smaller vessels, terminating in precapillary arterioles that then give rise to capillaries. Capillaries are comprised almost entirely of endothelial cells that are only occasionally coated by a smooth muscle cell-like pericyte. Capillaries then feed into postcapillary venules that progressively associate into larger and larger venous structures; venous structures are fully enveloped by smooth muscle cells, though not to the same degree as arterial structures.

The development of a functioning vascular network requires a remarkable degree of coordination between different cell types undergoing complex changes, and is exquisitely dependent upon signals exchanged between these cell types. Vascular endothelial growth factor (VEGF-A) provided the first example of a growth factor specific for the vascular endothelium, and VEGF-A has

${ }^{1}$ Corresponding author.

E-MAIL nick.gale@regpha.com; FAX (914) 347-5045. since been shown to be a critical regulator of endothelial cell development. Not surprisingly, the specificity of VEGF-A for the vascular endothelium results from the restricted distribution of VEGF-A receptors to these cells. The need to regulate the multitude of cellular interactions involved during vascular development suggested that VEGF-A might not be alone as an endothelial cell-specific growth factor. Indeed, there has been a recent explosion in the number of growth factors that specifically act on the vascular endothelium. This explosion involves the VEGF family, which now totals at least five members. In addition, an entirely unrelated family of growth factors, known as the Angiopoietins, recently has been identified as acting via endothelial cell-specific receptors known as the Ties. Most recently, particular members of the very large ephrin family have been identified as having unique roles on endothelium, and at least in some cases appear to act via a receptor that is not only largely restricted to the vascular endothelium but to the endothelium lining venous as opposed to arterial vessels.

As we describe in detail below, a variety of studies highlighted by the analyses of knockout mice (as summarized in Table 1) have implicated the VEGFs, the Angiopoietins, and the ephrins as critical players in particular aspects of vascular development.

\section{The VEGF family}

A series of recent papers provide excellent reviews of the VEGF family (Carmeliet and Collen 1999; Dvorak et al. 1999; Eriksson and Alitalo 1999; Ferrara 1999; Neufeld et al. 1999), so we offer only the basics herein. There are five characterized VEGF relatives in mammals (VEGF-A through VEGF-D, as well as PlGF), and they display differential interactions with three related receptor tyrosine kinases (VEGFR-1/Flt-1, VEGFR-2/KDR/Flk-1, and VEGFR-3/Flt-4) as summarized in Figure 1A; although not illustrated, ancillary receptor components, such as the neuropilins, also appear to be involved in these receptor complexes. VEGFR-1 and VEGFR-2 are restricted 
Table 1. Knockout animals from the VEGFR/VEGF, Tie2/Ang, and Eph/ephrin families have exhibited a variety of embryonic defects in vascular development

\begin{tabular}{|c|c|c|c|}
\hline Gene knockout & Time of death & $\begin{array}{l}\text { Stage of vessel } \\
\text { development }\end{array}$ & Causes of lethality \\
\hline VEGF-A (+/-) & E11.5 & $\begin{array}{l}\text { vasculogenesis/ } \\
\quad \text { (angiogenesis) }\end{array}$ & $\begin{array}{l}\text { reduced red blood cells; defective heart and aorta formation; } \\
\text { defective vessel connectivity; defective sprouting }\end{array}$ \\
\hline$V E G F-A(-/-)^{\mathrm{a}}$ & E10.5 & vasculogenesis & absent dorsal aorta; defective endothelial cell development \\
\hline VEGFR-1 & E8.5-E9.5 & vasculogenesis & failure of endothelial cell formation \\
\hline VEGFR-2 & E8.5-E9.5 & vasculogenesis & $\begin{array}{l}\text { excess endothelial cells form abnormal vessel structures } \\
\text { entering vessel lumens }\end{array}$ \\
\hline VEGFR-3 & E10.5-E12 & vasculogenesis & $\begin{array}{l}\text { defective vessel remodeling and organization; irregular large } \\
\text { vessels with defective lumens }\end{array}$ \\
\hline Ang1 & E10.5 & angiogenesis & $\begin{array}{l}\text { defective vessel remodeling, organization, and sprouting; heart } \\
\text { trabeculation defects }\end{array}$ \\
\hline Ang2 & $\mathrm{E} 12.5-\mathrm{P} 1$ & maturity & poor vessel integrity, edema, and hemorrhage \\
\hline Tie1 & $\mathrm{E} 13.5-\mathrm{P} 1$ & maturity & poor vessel integrity, edema, and hemorrhage \\
\hline Tie2 & E10.5 & angiogenesis & $\begin{array}{l}\text { defective vessel remodeling, organization, and sprouting; heart } \\
\text { trabeculation defects }\end{array}$ \\
\hline ephrin-B2 & E10.5 & $\begin{array}{l}\text { (vascuolgenesis)/ } \\
\text { angiogenesis }\end{array}$ & $\begin{array}{l}\text { some defective vessel primordia; defective vessel remodeling, } \\
\text { organization, and sprouting; heart trabeculation defects }\end{array}$ \\
\hline EphB2/EphB3 & E10.5 ( 30\%) & $\begin{array}{l}\text { (vascuolgenesis)/ } \\
\text { angiogenesis }\end{array}$ & $\begin{array}{l}\text { some defective vessel primordia; defective vessel remodeling, } \\
\text { organization, and sprouting; heart trabeculation defects }\end{array}$ \\
\hline EphB4 & E10.5 & $?$ & $?$ \\
\hline EphA2 & viable & - & - \\
\hline
\end{tabular}

Knockouts of VEGF and its receptors have yielded defects primarily in the early process of vasculogenesis, and accordingly these mutant embryos tend to die at early stages of development. In contrast, The Tie2 and Ang1 knockout embryos die at later stages and exhibit defects similar to each other, but with normal vasculogenesis, and perturbed angiogenesis. Deletion of Ang2, the putative natural antagonist of Ang1/Tie2 signaling, results in lethality at stages after the vascular system has undergone both vasculogenesis and angiogenesis. EphB2/B3 and ephrin-B2 knockout animals die primarily due to defects in angiogenesis similar to the Tie2 and Ang1 knockout embryos, although some defects in vasculogenesis were also reported. EphB4 mice die at similar stages. (VEGF-A) Carmaliet et al. (1996); Ferrara et al. (1996); (VEGFR-1) Fong et al. (1995); (VEGFR-2) Shalaby et al. (1995, 1997); (VEGFR-3) Dumont et al. (1998); (Ang1) Davis et al. (1996); Suri et al. (1996); (Ang2) C. Suri, J. McClain, M.V. Simmons, T.N. Sato, and G.D. Yancopoulos (in prep.); (Tie1) Puri et al. (1995); Sato et al. (1995); (Tie2) Dumont et al. (1994); Sato et al. (1995); (EphB2/EphB3) Orioli et al. (1996); Adams et al. (1999); (ephrin-B2) Wang et al. (1998); Adams et al. (1999); (EphB4) M. Aguet (in prep.); (EphA2) Chen et al. (1996).

${ }^{a}$ Because of the heterozygous lethality of heterozygous VEGF mutations, VEGF null (-/-) mice were generated by ES cell aggregation with tetraploid blastocysts resulting in contribution of the $\mathrm{VEGF}^{-/-}$cells to the embryo proper and not extraembryonic tissues. This difference in technology makes direct comparisons with the knockouts difficult. It might be predicted that contributions of VEGF from the extraembryonic $\left(\mathrm{VEGF}^{+/+}\right.$but tetraploid) tissues may have dampened the severity of the phenotype and allowed survival of the embryos to later stages of development.

largely to vascular endothelium in their expression, accounting for the specificity of action of this growth factor family. Interestingly, although VEGFR-3 is restricted largely to lymphatic endothelium (Kukk et al. 1996), mice that contain a knockout of the gene for VEGFR-3 display early embryonic lethality due to defects in the organization of large vessels prior to the emergence of lymphatics (Dumont et al. 1998).

The roles of VEGF-A and its receptors, VEGFR-1 and VEGFR-2, have been characterized in the most detail. In vitro, VEGF-A seems to have the ability to induce endothelial cell proliferation as well as migratory and sprouting activity, and to help promote endothelial cells to form tubule-like structures; these effects seem to be mediated largely by the VEGFR-2 receptor. Consistent with these in vitro actions, VEGF-A and VEGFR-2 are absolutely critical for the earliest stages of vasculogenesis in vivo, as blood islands, endothelial cells, and major vessel tubes fail to develop in appreciable numbers in embryos lacking either VEGF-A or VEGFR-2 (Shalaby et al. 1995; Carmeliet et al. 1996; Ferrara et al. 1996). Interestingly, even loss of a single VEGF-A allele results in embryonic lethality, demonstrating a remarkably strict dose-dependence for VEGF during development (Carmeliet et al. 1996; Ferrara et al. 1996). Because embryos heterozygous for the VEGF-A gene disruption are less affected than those homozygous for this mutation, analysis of these heterozygous mutant embryos has permitted insights into the continuing requirement for VEGF-A as development proceeds. This analysis has revealed that VEGF-A is involved not only in the very initial phases of vasculogenesis, but in later stages of vasculogenesis, in sprouting, and other aspects of angiogenesis, as well as in maintaining vessel survival (Carmeliet et al. 1996; Ferrara et al. 1996).

Mice lacking VEGFR-1 revealed a rather late role for 


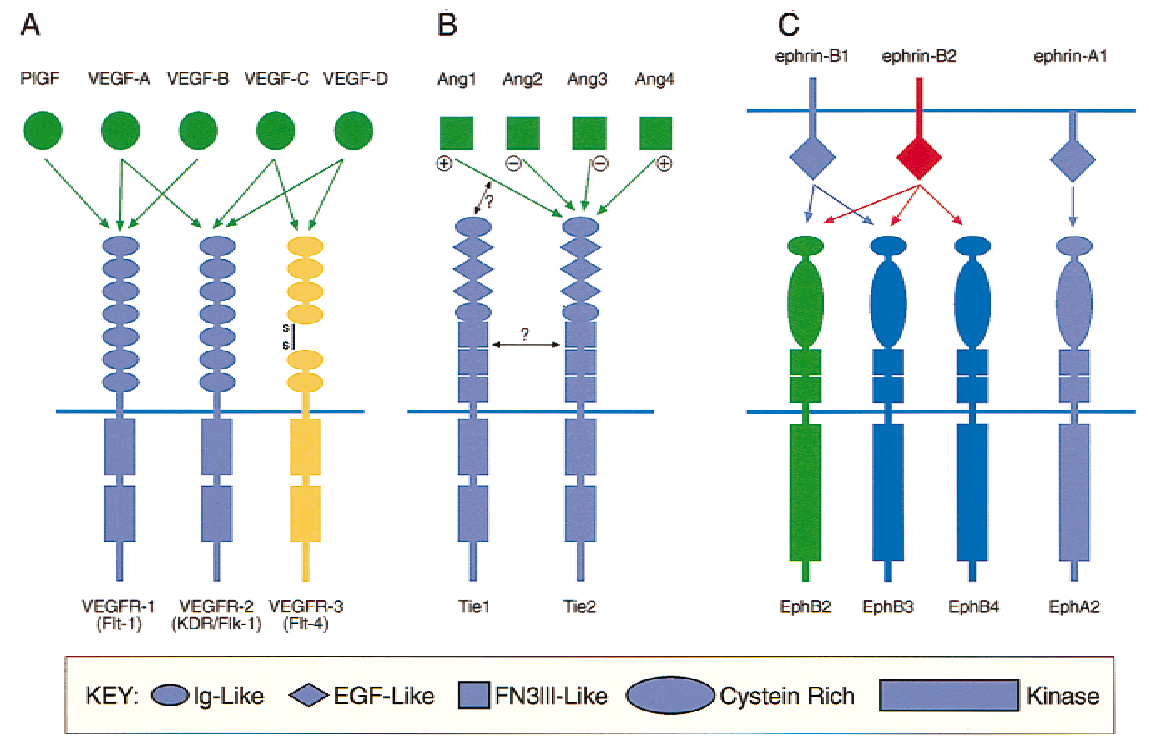

Figure 1. Ligands and RTK families involved in vascular development. (A) VEGFs and the VEGF receptors. $(B)$ The Angiopoietins (Ang) and Tie receptor family; $(C)$ The ephrins and Eph receptors. Arrows indicate documented interactions among ligands with their receptors. Note that receptor and ligand structures are drawn color coded to indicate their domains of expression; purple represents proteins found expressed on both arteries and veins. Red and blue structures are found on arteries and veins, respectively; yellow denotes expression in lymphatic vessels, and green structures represent receptors or ligands expressed in tissues surrounding blood vessels. Structural motifs present within the receptor families are indicated (not to scale) by the key. (FNIII) Fibronectin type III. Receptors of the Tie and VEGFR families exhibit kinases with intervening kinase inserts. The immunoglobulin-like (Iglike), or globular domain, of the Eph family receptors recently has been crystalized and shown to comprise a jellyroll $\beta$ sandwich motif (Himanen et al. 1999). this receptor as compared to VEGFR-2, as vessels do form in these mutant embryos, but are organized abnormally, with seemingly excess levels of endothelial cells being generated and entering into the lumens of the abnormal vascular channels (Fong et al. 1995). Thus, VEGFR-1 may actually be involved in down-regulating VEGF activity to ensure that the right numbers of endothelial cells are generated. Remarkably, mutant mice containing a VEGFR-1 lacking its tyrosine kinase domain allow for normal vascular development (Hiratsuka et al. 1998), indicating that only the binding portion of this receptor may be necessary to support its major actions during vascular development.

\section{The Angiopoietin family}

Long after the discovery of VEGF-A, a second family of growth factors specific for the vascular endothelium was identified, with members of this family termed the Angiopoietins (Davis et al. 1996; Suri et al. 1996; Maisonpierre et al. 1997; Valenzuela et al. 1999). Similar to VEGF, the specificity of the Angiopoietins for the vascular endothelium results from the restricted distribution of the Angiopoietin receptors, Tie1 and Tie2, to these cells. Tie1 and Tie2 are receptor tyrosine kinases just as are the receptors for VEGF. The four known Angiopoietins all bind to Tie2, but it is still unclear as to whether they utilize the closely related receptor Tiel (Fig. 1B). The Angiopoietins provide the first vertebrate example of a growth factor family consisting of both receptor activators as well as receptor blockers, with Angiopoietin-1 (Ang1) and Angiopoietin-2 (Ang2) providing the best characterized examples of an activator and a blocker in this system (Fig. 1B). The existence of both activators and blockers of the Tie2 receptor suggested early on that turning off this receptor might prove to be just as important as turning it on.

The actions of the Angiopoietins appear to be quite different from those of VEGF. Most notably, in vitro analyses on cultured endothelial cells revealed that Ang1 could not elicit standard mitogenic responses as can VEGF-A, nor induce tubule formation, although it could apparently promote endothelial cell sprouting in vitro (Davis et al. 1996; Koblizek et al. 1998). Consistent with these in vitro results, in vivo studies reveal that Ang1 seems to act in complementary and coordinated fashion with VEGF, having a later role in vascular development. Thus, in mouse embryos lacking either Ang1 or Tie2, the early stages of VEGF-dependent vascular development appear to occur rather normally, resulting in the formation of a primitive vasculature (Dumont et al. 1994; Sato et al. 1995; Suri et al. 1996). However, remodeling and stabilization of this primitive vasculature is severely perturbed, leading to embryonic lethality (Sato et al. 1995; Folkman and D'Amore 1996; Suri et al. 1996); defects were particularly obvious in the capillary plexi of the yolk sac and head. These defects are thought to result from disruptions in Ang1-mediated interactions between endothelial cells and surrounding support cells such as smooth muscle cells; support cells produce the Ang1 that paracrinely acts on endothelial cells expressing Tie2 receptors. Ultrastructural examination of vessels in mice lacking Ang1 showed that endothelial cells failed to interact and adhere properly to underlying support cells, and that the endothelial cells appeared rounded in appearance and as if they were detaching from underlying support cells and matrix; in the absence of such optimized cellular interactions, vessels apparently failed to 
undergo normal remodeling events and apparently were also at risk for subsequent regression. Another major defect in mice lacking Ang1 or Tie2 involves heart development. Normal heart ventricles exhibit extensive finger-like projections of the myocardial wall, known as trabeculations, which are lined by coronary endothelal cells (endocardial cells), the specialized endothelium of the heart. In embryos lacking Ang1 or Tie2, myocardial trabeculations fail to form, and the endocardium appears detached from the underlying myocardium, perhaps reflecting poor attachment. A similar heart defect was also reported in mice lacking neuregulin or its receptor (Gassman et al. 1995; Lee et al. 1995; Meyer and Birchmeier 1995; Kramer et al. 1996), which led to the proposal of a required growth factor loop in trabecular formation involving both an endocardial-derived ligand acting on the myocardium, that is, neuregulin, and a myocardial-derived factor acting on the endocardium, that is, Ang1 (Suri et al. 1996).

Altogether, the defects in mice lacking Ang1 or Tie2 suggest that this system is critical for normal remodeling, maturation, and stabilization of the developing vasculature. It has been suggested that the Angiopoietins themselves may not be 'instructive' remodeling signals but are simply 'permissive' in that they allow for proper interactions between endothelial cells and supporting cells, resulting in a system that can then properly respond to other cues (Suri et al. 1996). In the absence of proper interactions between endothelial cells and their support cells, defects arise, whether in particular vascular beds or in a developing vascular structure such as the heart. Consistent with the notion that Ang1 may continue to play a required stabilizing role for mature vessels, Ang1 seems to be constitutively expressed in the adult. Interestingly, transgenic overexpression of Ang1 leads to striking hypervascularization, presumably by promoting vascular remodeling events and perhaps by decreasing normal vascular pruning (Suri et al. 1998).

Shortly after the discovery of Ang1, the cloning of Ang2 was described (Maisonpierre et al. 1997). Remarkably, although Ang2 bound to the Tie2 receptor as did Ang1, it could not activate it. Instead, Ang2 provided the first example of a naturally occurring antagonist for a vertebrate tyrosine kinase. Consistent with the notion that Ang2 acts as a natural antagonist for the Ang1/Tie2 interaction, transgenic overexpression of Ang2 during embryogenesis leads to a lethal phenotype reminiscent of that seen in embryos lacking either Ang1 or Tie2, with severe disruptions in vascular development (Hannahan 1997; Maisonpierre et al. 1997) .

Examination of Angiopoietin expression patterns in vivo suggested a very interesting role for Ang2 at sites of vascular remodeling in an otherwise stable adult vasculature (Maisonpierre et al. 1997). Whereas Ang1 is expressed widely in normal adult tissues, consistent with it playing a continuously required stabilization role, Ang2 is highly expressed only at sites of vascular remodeling in the adult, notably in the female reproductive tract (Maisonpierre et al. 1997). Detailed localization of Ang2 in the ovary by in situ hybridization revealed that in regions of active vascular remodeling it was either expressed together with VEGF at sites of vessel sprouting and ingrowth (e.g., developing corpus luteum), or in the absence of VEGF at sites of frank vessel regression (e.g., atretic follicles). These expression patterns led to the proposal of a model in which Ang2 plays a facilitative role at sites of vascular remodeling in the adult by blocking a constitutive stabilizing action of Ang1, allowing the vessels to revert to a more plastic and unstable state (Maisonpierre et al. 1997). Furthermore, it was suggested that such destabilization by Ang2 in the presence of high VEGF levels primes the vessels to mount a robust angiogenic response reminiscent to that of early embryonic vessels prior to maturation (Maisonpierre et al. 1997). However, such destabilization by Ang2 in the absence of VEGF is instead proposed to lead to frank vessel regression.

Altogether, existing data suggest that VEGF-A and Angiopoietins not only have quite different roles during vascular development, but also very complementary and coordinated roles.

\section{The ephrins}

Among the known families of receptor tyrosine kinases (RTKs) and their ligands, the Eph receptors and their ligands the ephrins stand out in many ways (Fig. 1C). The Eph receptors comprise the largest subfamily of RTKs, including at least 14 distinct members in both man and mouse; Eph receptors and ligands have also been described in invertebrates such as Drosophila and Caenorhabditis elegans (George et al. 1998; Flanagan and Vanderhaeghen 1998). The Eph receptors are quite divergent in sequence from other RTKs and are closely related to cytoplasmic tyrosine kinases within their kinase domains (Hanks and Quinn 1991). Although all the Eph receptors were initially isolated as orphan receptors, lacking known ligands, this situation has changed dramatically over the past 5 years. At least eight Eph receptor ligands-ephrins-have been described. The ephrins, like their receptor counterparts, are also rather unique among RTK ligands. Most notably, they do not function as typical soluble ligands for their receptors but, rather, must normally be membrane attached to activate their receptors (Davis et al. 1994; Gale and Yancopoulos 1997). Membrane attachment seems to promote clustering or multimerization of the ligands, and it is this clustering that seems to be necessary to activate receptors on adjacent cells (Davis et al. 1994). Consistent with this notion, whereas monomeric soluble ligands seem to act as antagonists, artificial clustering of soluble versions of these ligands can allow them to activate their receptors (Davis et al. 1994; Winslow et al. 1995). All of the known ephrins are tethered naturally to the cells in which they are expressed. It is these two different attachment mechanisms, along with shared homology and binding characteristics, that divide them into two subgroups, the ephrin-A and ephrin-B subgroups (Brambilla et al. 1995; Gale et al. 1996a,b; Eph Nomenclature Committee 1997). The ephrin-B subgroup, comprised of three mem- 
bers, ephrin-B1 through ephrin-B3, possesses transmembrane as well as highly conserved cytoplasmic domains, whereas the ephrin-A subgroup, comprised of five members, ephrin-A1 through ephrin-A5, is attached to the outer leaflet of the plasma membrane via a glycosylphoshotidylinositol (GPI) anchor. The ephrin-A subgroup exhibit rather general and promiscuous binding to the EphA receptors (EphA1 through EphA8), and the ephrin-B subgroup exhibits a general binding preference for the receptors of the B subgroup (EphB1 through EphB6). There are a few exceptions to these general binding predelictions. Some receptors are even more promiscuous in that they can bind across subgroups, whereas other receptors display unusually restricted specificity. Notable examples of these two exceptions include EphA4, which binds not only the ephrin-A ligands but several of the ephrin-Bs as well (Gale et al. 1996a,b), and EphB4, which selectively binds ephrin-B2 and not the other ephrin-B ligands (Brambilla et al. 1995; Sakano et al. 1996).

A fascinating series of experiments have suggested that the ephrin-B ligands perhaps should be not only thought of as ligands but as signaling receptors as well. This idea arises because when ephrin-B ligands engage Eph receptors, the ephrin-B ligands themselves become tyrosine phosphorlated and presumably activate signaling within the cells in which they are expressed (Holland et al. 1996; Brukner et al. 1997). Although it is not as intuitively obvious that similar bidirectional signaling events may be occurring with the ephrin-A ligands, owing to their lack of a membrane spanning segment, there is some precedent for other GPI-anchored molecules to transduce signals into the cells to which they are attached (for example, see Brown 1993). Together, these findings clearly blur the distinction between receptor and ligand, and complicate things in a most interesting way, being that one must keep in mind the notion that signaling from Eph receptors and their ligands is capable of being a reciprocal bidirectional event between interacting cells.

Because bidirectional signaling apparently occurs between Eph receptors and ephrin-B ligands, and because this coactivation seemingly depends on clustering of both these membrane-bound partners, it is quite intriguing that molecular mechanisms have recently been described that may allow for regulating such clustering. It has been shown that both Eph receptors and ephrin-B ligands have recognition motifs, at their carboxyl termini, that allow for binding of PDZ domain-containing proteins (Hock et al. 1998; Torres et al. 1998; Buchert et al. 1999; Lin et al. 1999). PDZ domains are modular protein-interaction domains that typically recognize short peptide sequences of four or more amino acids at the very carboxyl terminus of target proteins, and are known to be involved in regulating clustering events among themselves and the protein with which they interact. PDZ interactions can cluster both Eph receptors and ephrin-B ligands and also appear to localize the Eph receptors to synapses in the CNS where they may modulate synaptic functions (Hock et al. 1998; Hsueh and Sheng 1998; Torres et al. 1998; Buchert 1999|. PDZ bind- ing has not been described previously for other mammalian RTKs or their ligands, although it appears that other RTKs that are clustered at synapses may also bind PDZ proteins (Torres et al. 1998; Buchert et al. 1999).

In addition to their PDZ interaction motifs, Eph receptors contain another motif that may mediate receptor clustering. The carboxyl terminal region of Eph receptors also includes a sterile $\alpha$ motif (SAM) (Schultz et al. 1997). The crystal structure of Eph family SAMs recently have been described and suggest that these are protein-protein interaction modules that may be involved in modulating receptor oligomerization, as well as interaction with cellular signaling complexes (Stapleton et al. 1999; Thanos et al. 1999).

\section{Eph family function during development}

Like the Angiopoietins, ephrins seem unlike most other RTK ligands in that they can not induce potent mitogenic responses from target cells, suggesting that they too are involved in other types of biological processes. Ephrins also seem quite unusual in that they are obligated to act in membrane-bound form, restricting ephrin/Eph interactions to sites of direct cell-cell contact. Consistent with the notion of unusual roles for this family of RTK ligands, to date they have been most solidly implicated in the process of neural cell guidance. For example, Eph receptors and ligands seemingly regulate axon guidance events that establish the retinotopic map in the tectum (for review, see O'Leary et al. 1999). They have also been shown to be involved in the guidance of neural crest cells as they navigate through the trunk and branchial regions of the developing embryo (Krull et al. 1997; Robinson et al. 1997; Smith et al. 1997; Wang and Anderson 1997). The Eph family has also been implicated more generally in patterning of the brain and somites, where they are predicted to have roles in regulating cell mixing and establishing boundaries between distinct cellular compartments (Xu et al. 1995, 1996; Durbin et al. 1998; Gale et al. 1996b). By and large these biological actions of the Eph family can be explained as resulting from repulsive interactions between receptor and ligand-bearing cells, or instead a signal that prevents two adjacent cell types (reciprocally expressing and Eph receptor and a cognate ligand) from intermixing across a boundary (Gale and Yancopoulos 1997). Recently, localization of Eph family members to synapses suggests that they may play an important role not only in guiding neuronal processes to their connections, but in continuing to regulate these connections once they have formed (Hsueh and Sheng 1998; Torres et al. 1998; Buchert et al. 1999).

Several recent studies on ligand and receptor knockouts in mice, in conjunction with some earlier in vitro studies, now suggest that some Eph family members play roles during vascular development that are at least as critical as those served by Eph family members during neural development. It is on these roles that this review will next focus, as we attempt to place these roles in 
context with those played by the VEGFs and the Angiopoietins.

\section{Early in vitro findings suggesting Eph involvement in vascular biology}

The first known ephrin, ephrin-A1 (at that time termed B61), was first isolated as a protein of unknown function that was induced in endothelial cells following treatment with tumor necrosis factor (Holzman et al. 1990), and subsequent expression studies revealed a rather specific pattern of expression of ephrin-A1 in the developing vasculature (Flenniken et al. 1996; McBride and Ruiz 1998). Additional studies showed that although ephrinA1 had no discernible mitogenic effects on cultured endothelial cells, it could promote their chemotaxis and induce sprouting in a rat cornea pocket assay (Pandey et al. 1995). It was also shown that ephrin-A1 could promote capillary-like assembly of human umbilical vein endothelial cells (HUVEC) in an in vitro tubule-formation assay (Daniel et al. 1996). Similar studies showed that ephrin-B ligands could also induce tubule formation, but only on different class of endothelial cells derived from human renal microvasculature (HRMEC). Thus, whereas ephrin-A1 induces HUVECs but not HRMECs to form tubules, ephrin-B1 does the same from HRMECs but not HUVECs (Daniel et al. 1996). Subsequent studies established that EphB class receptors are capable of discriminating between the density or the extent of ligand oligomerization, and mediate tubule assembly in response to tetrameric versions of ligand, but not dimeric forms (Stein et al. 1998b). Linking ephrins to VEGF and the Angiopoietins, B-ephrins were shown to induce sprouting in the same in vitro assay previously used to demonstrate VEGF and Angiopoietin actions (Adams et al. 1999). Linking ephrins to integrin function, a very recent study shows that B-eprhins can promote attachment of endothelial cells to extracellular matrix components by activating integrin function (Huynh-Do et al. 1999). Because blocking integrin function has been shown to disrupt many different aspects of angiogenesis, it is intriguing to consider that the Eph family can regulate integrin function on endothelial cells, and also tempting to speculate that integrin reguation can also be important for Eph function in neural and developmental settings.

\section{Ephrin-B2 and EphB4 differentially mark arterial and venous endothelial cells}

Although the above findings suggested that ephrins might have a role during vascular development, recent knockout studies of ephrin-B2 and EphB2/EphB3 now firmly establish Eph family members as key players in the process of embryonic vascular development (Wang et al. 1998; Adams et al. 1999).

The initial report of an ephrin-B2 knock out mouse created a great stir among Eph researchers as well as those working in the field of vascular biology (Wang et al. 1998). In this study the ephrin-B2 gene was replaced by the lac $Z$ gene, thus providing an excellent marker for precisely following the expression of ephrin-B2. 1acZ expression analysis revealed that ephrin-B2 specifically marked arterial endothelial cells at the earliest stages of vascular development (Wang et al. 1998). This finding sparked examination of the expression patterns for EphB receptors, which revealed that EphB4 (which only binds to ephrin-B2, see above) specifically and reciprocally marks only the venous endothelium (Wang et al. 1998). Furthermore, the embryos lacking ephrin-B2 displayed severe defects in the vascular remodeling, subsequent to the initial stages of vasculogenesis, in both arterial and venous domains. It was suggested that the observed vascular defects arose from defects in bidirectional signaling, normally mediated by the reciprocally expressed ephrin-B2 and EphB4, that occurs between arterial and venous vascular beds during embryonic angiogenesis.

The discovery of clear molecular differences in arterial and venulous endothelial cells at such early stages of development, when the vasculature appears in many areas to be a uniform plexus of interconnected tubules in which there is no clear morphological distinction between presumptive arterial and venous domains, was quite unexpected. Though molecular differences in arterial and venule endothelium is clearly noted at later stages, when these cells can be distinguished by differential lectin staining (Thurston et al. 1996), it was conceivable that such differences reflected late-acting physiological influences such as blood flow, pressure, shear forces as well as relative oxygen content. The ephrin-B2/ EphB4 expression studies suggest that molecular differences are at least in part programmed genetically in arterial versus venous endothelium, and furthermore that these differences may be critical to normal development of the vasculature.

\section{Vascular defects in mice lacking ephrin-B2, and similarities to defects on mice lacking Ang1 or its receptor Tie2}

The ability to distinguish arterial versus venous endothelium at very early stages, which had previously not been possible due to the absence of specific arterial markers, revealed an unexpectedly high degree of interdigitation of arterial and venous vessels in the primary capillary plexus of the early yolk sac of normal embryos (Wang et al. 1998). Interestingly, generation of the primary capillary plexus occurred in the yolk sac of embryos lacking ephrin-B2, and this plexus was still divided in its expression of the newly defined arterial and venous markers. However, interdigitation of arterial and venous vessels in this plexus was absent in mice lacking ephrin$\mathrm{B} 2$, and remodeling of the primary yolk sac plexus into large and small branches also did not occur, consistent with a critical role for ephrin-B2 in these processes. It was also observed that yolk mesenchymal and periendothelial cells appeared to be poorly associated with the endothelium, and exhibited a rather rounded morphology in comparison to wild-type mesenchyme. Here it 
appeared as though arterial vessels failed to delaminate from endodermal layers, and in some cases vessels were dilated and appeared to lack the normal complement of supporting cells (Wang et al. 1998). Altogether, the formation of an initial plexus in the yolk sac, coupled with defects in later remodeling that were marked by problems with endothelial cell interactions with support cells, was highly reminiscent of defects observed in mice lacking Angl or its receptor Tie2 (Sato et al. 1995; Suri et al. 1996; see above).

Defects elsewhere in the ephrin-B2-deficient embryos were also reminiscent of those in mice lacking Ang1 or its Tie2 receptor. Outside of the yolk sac, these defects were documented most carefully in the primary capillary plexus in the developing head region. In contrast to the yolk sac, the head plexus appeared rather devoid of cells of arterial origin in ephrin-B2 mutants (with the exception of the most proximal branches of the internal carotid artery), and was thus presumably mostly venous in origin. Although some of the venous vessels (e.g., the most proximal branches of the anterior cardinal vein) underwent morphogenesis in ephrin-B2 mutants, these vessels appeared abnormal, with distal branches remaining dilated and unorganized (Wang et al. 1998). These results, like those in the yolk sac, suggest that interactions between arteries and veins (and mediated by ephrin-B2) are important for the normal remodeling of the head vasculature; however the manner in which these interactions occur appears to be fundamentally different than those in the yolk sac. Another aspect of angiogenesis, known as sprouting angiogenesis, is responsible for the ingrowth vessels into previously avascular areas of the embryo, such as the neural tube. In ephrin-B2 knockout animals, no angiogenic sprouts are observed in the neurectoderm. In the case of sprouting angiogenesis into the neurectoderm it was proposed that perhaps vascular spouts of arterial origin (i.e., expressing ephrin-B2) normally interact with EphB receptors, such as EphB2, expressed in the neurectoderm, and that this interaction somehow promotes vessel growth into this tissue (Wang et al. 1998).

Finally, embryos lacking ephrin-B2 displayed defects in heart trabeculation quite analogous to those described in mice lacking Ang1 or neuregulin (Gassman et al. 1995; Lee et al. 1995; Meyer and Birchmeier 1995; Kramer et al. 1996; Wang et al. 1998; Zhao and Lemke 1998). The expression pattern of ephrin-B2 and its receptors in the heart is quite complex and does not conform to a simple arterial/venous distribution pattern, though it remains possible that the distributions are still complementary and that the heart abnormality is due to the same basic defect in cell signaling that accounts for the abnormalities elsewhere in the vasculature. In any case, the realization that ephrin-B2 is also involved in myocardial trabeculation adds another requisite growth factor to this process, but our inability to assign even a sequence to the actions of the three known requisite growth factors (neuregulin, Ang1, and ephrin-B2) emphasizes how little we understand about the process of trabecular formation. Likewise, despite the similarities be- tween many of the vascular remodeling defects resulting from disruption of either ephrin or Angiopoietin signaling, it remains difficult to even order the actions of these two growth factor systems. It seems possible that the Angiopoietin system may act upstream of ephrin-B2, but the reverse is also plausible. However, since Angiopoietins and Ties have not been reported to display asymmetric distributions, it seems unlikely thatAngiopoietins directly establish ephrin-B2/EphB4 expression patterns, or vice versa; nevertheless, it will be fascinating to examine ephrin-B2 expression patterns in the Ang/Tie2 knockouts. It also remains possible that the ephrin and Angiopoietin systems act in largely independent fashions, disruption of either of which leads to a similar phenotype. For example, since it has been proposed that the Angiopoietins themselves may not be instructive but rather permissive, in that they allow for proper interactions between endothelial cells and supporting cells resulting in a system that can then properly respond to other cues, it is possible that ephrin-B2 may be just such an instructive cue that requires prior permissive actions of the Angiopoietins.

\section{The roles of ephrin-B2 and EphB4 in vascular remodeling: developing more complications}

Despite the remarkably reciprocal expression of ephrinB2 and its EphB4 receptors in developing arterial and venous endothelium, it remains completely unclear as to precisely where and how the critical interactions occur between cells expressing these signaling partners (Wang et al. 1998; Yancopoulos et al. 1998). Because both partners are membrane bound, it is presumed that signaling must be occurring at sites of cell-cell contact. Thus, although critical signaling could be occurring within individual tubules precisely at the junction of arterial and venous cells (cis interactions, Fig. 2), ephrin-B2/EphB4 interactions could also be occurring as developing tubules pass each other, or as a developing sprout touches an adjacent tubule (trans-interactions, Fig. 2).

To complicate matters even further, an independent report of an ephrin-B2 gene deletion confirmed the overall phenotype initially described by Wang et al. (1998) but raised many additional issues (Adams et al. 1999). The later study raised the question of whether other ligands and receptors in the B subgroup also played crucial roles in vascular development along with ephrin-B2 and EphB4, and whether these B-class receptors and ligands were critical not only for interactions between arterial and venous endothelial cells, but for interactions between endothelial cells and surrounding cells and tissues (Adams et al. 1999). These questions arose because Adams et al. (1999) found that other B-class receptors and ligands displayed expression patterns overlapping those for ephrin-B2 and EphB4, and also found that embryos lacking both EphB2 and EphB3 exhibited defects in vascular development that largely phenocopy those of the ephrin-B2 knockouts (Adams et al. 1999). That is, with a penetrance of $\sim 30 \%$, embryos lacking EphB2 and EphB3 (EphB2/B3) displayed defects similar to those of ephrin- 
Figure 2. Expected interactions of Eph family members on arteries, veins, and mesenchyme. Arteries express ephrin-B1 and ephrin-B2, whereas veins express EphB3 and EphB4, and ephrin-B1 (see keys). Veins and arteries and the cells within a given vessel can interact with each other in several ways, and these interactions would be expected to bring Eph family members in contact with each other in several ways. Interactions between cells of a given vessel, which we term cis interactions $(B-D$, center $)$, will occur among venous cells in veins and arterial cells in arteries. In the special case of capillaries, where vessels switch between arterial and venous domains, arterial and venous cells will also contact one another within a single vessel. Interaction between distinct arterial and venous vessels in regions where they grow closely together or contact each other by sprouting will also bring cells expressing Eph family members into contact with each other in a trans configuration $(A, C, D)$. Additional important interactions occur when arterial or venous sprouts interact with surrounding mesenchymal cells, which express EphB2 and ephrin-B2 (shown) and most likely other family members as well $(E, F)$. It is important to note that the distinction between Eph receptors and their ligands is somewhat arbitrary in that both components are capable of signaling when bound to their counterparts; thus, signals between arteries, veins, and mesenchyme will be bidirectional. In addition, in the case of vein cell interactions with other venous cells, and mesenchymal cells signaling can theoretically be reciprocal, because both interacting cells express receptors as well as ligands.

B2 knockout mice in the primary plexi of the yolk sac and head, and in heart morphogenesis. However, sprouting angiogenesis into the neural tube was normal in EphB2/B3 knockout mice, in contrast to the situation in embryos lacking ephrin-B2.

Whereas Wang et al. (1998) portrayed a relatively simple picture in which arterial endothelium expresses ephrin-B2 and venous endothelium expresses EphB4, and suggested that other B-class receptors and ligands were not involved in this system, Adams et al. (1999) described a much more complex situation. While confirming the remarkable specificity of ephrin-B2 and EphB4, Adams et al. (1999) show that several other B-class receptors and ligands are expressed in and around the developing vasculature. In particular they reported that ephrin-B1 is coexpressed with ephrin-B2 on arterial endothelium (Fig. 2), though its presence there obviously is not sufficient to compensate for the knockout of ephrinB2. In addition, in a few locations, such as the aortic arches, they reported that the EphB3 receptor is also expressed in arteries. In veins, they claim that EphB3 appears to be broadly expressed and overlaps the expression of EphB4, and that ephrin-B1 is also expressed in veins in addition to its expression in arteries (Fig. 2). Thus venous endothelium seems to generally express both EphB3 and EphB4 receptors as well as an ephrin-B ligand, and arterial endothelium expresses both ephrin-B1 and ephrin-B2 as well as expression of EphB3 in some limited sights [e.g., in aortic arches (Adams et al. 1999)]. To complicate things even further they report expression of Eph family members in tissues surrounding vessels at sites of sprouting angiogenesis, such as in the somites and the neural tube. The remarkably reciprocal expression patterns of ephrin-B2 and EphB4, together with the strict specificity of EphB4 for binding only to ephrin-B2, seem to undeniably support a unique role for this set of partners (Fig. 2). However, the widespread expression patterns of other B-class Eph family members, together with the phenotypes of mice lacking EphB2 and EphB3, indicate that other B-class family members also play critical roles in vascular development. These roles may in some ways overlap with those of ephrin-B2 and EphB4 and, at least for ephrin-B2, may also involve binding to it as well. Furthermore, in addition to cis or trans interactions between arterial and venous endothelial cells, the expression of B-class Eph family members in surrounding tissues suggests that Eph-mediated interactions between endothelium and surrounding cells might be very critical (Fig. 2). For example, sprouting angiogenesis into somites appears to provide a specific example in which ephrin-B2 expressed not by endothelium, but rather in surrounding mesenchyme, interacts in a critical manner with EphB4 and EphB3 receptors on vessels (Adams et al. 1999). It has been shown that ephrin-B2 is expressed in the posterior half of the somitic sclerotome as well as in the dermomyotome, and its presence there has been demonstrated to be involved in the guidance of both motor axons and neural crest cells which negotiate their way through the sclerotome during development (Krull et al. 1997; Wang and Anderson 1996). Here the ephrin repels these cells or processes from the posterior somite and presumably channels them along their appropriate pathway through the anterior somite (Krull et al. 1997; Wang and Anderson 1997). Such repulsive interactions 
may likewise occur in the vasculature, because vessels that develop within/around somites express EphB3 and EphB4 and are observed to grow in close association with, but not within, domains of expression of ephrin-B2 in the dermomyotome in wild type mice. In addition, intersomitic vesses exhibit abnormal projections into the somites in ephrin-B2 knockout mice, where the putative inhibitor is absent (Adams et al. 1999). Likewise embryos devoid of EphB2 and EphB3 exhibit aberrant patterns of sprouting from intersomitic vessels into the neighboring somites (Adams et al. 1999). Because abnormal sprouting into somites is seen in mutants lacking ephrin-B2 or the EphB2/EphB3 receptors, these interactions presumably normally suppress sprouting (Adams et al. 1999|. Thus, somitically expressed ephrin-B2 may serve similar repulsive functions in both neural and vascular pathfinding in the region of somites.

Altogether, the findings of Adams et al. (1999) complicate the simple picture initially portrayed by Wang et al. (1998) raising the possibility that many different types of interactions, involving different B-class Eph family members as well as different types of cells, might play critical roles during vascular development (Fig. 2). It is also worth reiterating that all of these interactions are further complicated by the possibility of bidirectional signaling in all cases, making it difficult to understand which cell is sending the signal and which is receiving it.

It is also worth noting that although Adams et al. (1999) confirmed the claim of Wang et al. (1998) that most of the defects in the ephrin-B2 knockout represent abnormalities in angiogenic processes as opposed to earlier vasculogenic processes, Adams et al. also report additional defects that seem to primarily involve vasculogenesis (Table 1). For example, they report defects in major vascular structures formed by vasculogenesis, such as the anterior cardinal vein, the fourth arch of the aorta, and in some cases the dorsal aorta itself; in some severe cases they found that embryos lacking ephrin-B2 had no dorsal aorta or just a single vessel, rather than the normally paired structures (Adams et al. 1999). Furthermore, they reported that many of the embryos lacking EphB2 and EphB3 also had defects in the primordia of major vessels, such as the anterior cardinal vein and the aortic arches.

Despite the remarkably specific expression of EphB4 in venous endothelium, its overlapping expression with other EphB receptors in veins, together with the variable penetrance of the phenotypes displayed by EphB2 and EphB3 knockout mice, raised the question of whether EphB4 was as crucial to vascular development as ephrinB2. The preliminary answer may soon be provided by the generation of mice lacking EphB4, which are reported to display an early embyronic lethal phenotype (M. Aguet, pers. comm.). One clearly might predict that this phenotype may arise due to vascular defects in angiogenesis (Table 1). A detailed comparison of such defects with those in mice lacking ephrin-B2 and EphB2/EphB3 should prove quite interesting. It will also be interesting to examine mice lacking ephrin-B1 for any vascular phenotypes, which would be predicted due to the wide- spread expression of this ligand in both arteries and veins.

It is in part surprising that deletion of EphB4 alone results in such a dramatic phenotype, because Eph receptor knockout animals have historically not exhibited overt phenotypes when deleted singly, presumably due to compensation by other family members (e.g., Chen et al. 1996; Henkemeyer et al. 1996; Orioli et al. 1996; Park et al. 1996; N.W. Gale and G.D. Yancopoulos, unpubl.). EphB4 may be a special case due to the high degree of specificity of EphB4 for ephrin-B2. Alternatively it may be due to unique signaling capabilities of EphB4 that cannot be compensated by the overlapping expression of EphB3 in veins.

\section{Conclusions}

Three different growth factor systems have been described that act via endothelial cell-specific receptor tyrosine kinases. As might be expected, these three different growth factor systems seem to have very different roles during vascular development. The VEGF system seems to be absolutely required for the earliest stages of vasculogenesis, although it continues to play a critical role during subsequent angiogenesis. VEGF seems able to elicit differentiative, proliferative and chemotactic responses from endothelial cells, as well as to promote the coalescence of endothelial cells into primitive vascular structures. Unlike VEGF, Ang1 cannot promote mitogenic responses or tubule formation. In fact, Ang1 seems to come into play after VEGF, by acting to promote vessel branching and remodeling, as well as to promote maturation and stabilization of vessels. Critical to the function of Angl appears to be its ability to optimize interactions of endothelium with surrounding support cells and matrix, thus stabilizing and maintaining vessels, which it appears to constitutively do in the adult. Ang1 has a natural antagonist, Ang2, which seems to be induced in adult settings of neovascularization, apparently blocking the stabilizing effect of Ang1 and thus allowing vessels to revert to a more plastic state where they are more responsive to VEGF, but also subject to regression in the absence of VEGF. Existing data suggest that VEGF and Angiopoietins act in a very complementary and coordinated fashion. Like the Angiopoietins, the ephrins also seem to primarily act in later stages of vascular development, though they may also contribute somewhat to formation of vessel primordia. Currently, the most striking aspect of the Eph family in regards to the vasculature is the reciprocal expression of ephrin-B2 and its receptors EphB3 and EphB4 differentially marking arterial and venous endothelium. However, several different ephrins, of both the A and B subgroups, appear to be involved in vascular development and in some cases display overlapping expression with ephrin-B2 and EphB3 and EphB4. Although it is clear that complimentary expression patterns play important roles, sites of overlapping expression of receptors and their ligands, though not well understood at present, will undoubtedly also prove to be mechanistically important. 
Though some of the defects seen in mice lacking ephrins and Eph receptors resemble those seen in mice lacking Ang1, ordering the actions of ephrins and Angiopoietins, or even understanding if these actions are linked in some way, remains very difficult. Part of the difficulty stems from the lack of mechanistic understanding of Eph family function. It is clear that the Eph family functions in the context of cell-cell contact, and that most of the actions of the Eph family in the CNS can be explained by assuming that they are providing a repulsive signal, or a signal which somehow prevents two adjacent and differentially marked cell types from intermixing; these signals may depend on the ephrin density and degree of clustering, and may involve bidirectional signaling. It will be interesting to see if Eph family function in the vascular system conforms to these emerging views of its function in the nervous system.

A relatively unexplored area of study for these three growth factor families involves their mechanisms of intracellular signaling in endothelial cells, and whether they employ any unique pathways. Of particular interest for the Angiopoietins and ephrins will be the way they may regulate cytoskeletal plasticity, matrix attachment, and intercellular adhesions, as well at the involvement of integrins in these processes.

Precise understanding of how all these various growth factor systems coordinately act during vascular development, and how this process is integrated with growth of the entire embryo, is sure to keep vascular developmental biologists enthralled for years to come.

\section{Acknowledgments}

We thank the various members of the Regeneron community for their support and discussions, especially Evan Burrows and Claudia Murphy, for excellent assistance with graphics. We are also grateful to Tom O. Daniel and Michel Aguet for sharing results prior to publication.

\section{References}

Adams, R.H., G.A. Wilkinson, C. Weiss, F. Diella, N.W. Gale, U. Deutsch, W. Risau, and R. Klein. 1999. Roles of ephrinB ligands and $\mathrm{EphB}$ receptors in cardiovascular development: Demarcation of arterial/venous domains, vascular morphogenesis, and sprouting angiogenesis. Genes \& Dev. 3: 295306.

Brambilla, R., A. Schnapp, F. Casagranda, J.P. Labrador, A.D. Bergemann, J.G. Flanagan, E.B. Pasquale, and R. Klein. 1995. Membrane-bound LERK2 ligand can signal through three different Eph-related receptor tyrosine kinases. EMBO $J$. 14: 3116-3126.

Brown, D. 1993. The tyrosine kinase connection: How GPIanchored proteins activate T-cells. Curr. Opin. Immunol. 5: $349-354$

Bruckner, K., E.B. Pasquale, and R. Klein. 1997. Tyrosine phosphorylation of transmembrane ligands for Eph receptors. Science 275: 1640-1643.

Buchert, M., S. Schneider, V. Meskenaite, M.T. Adams, E. Canaani, T. Baechi, K. Moelling, and C.M. Hovens. 1999. The Junction-associated protein AF-6 interacts and clusters with specific Eph receptor tyrosine kinases at specialized sites of cell-cell contact in the brain. J. Cell Biol. 144: 361-371.

Carmeliet, P. and D. Collen. 1999 Role of vascular endothelial growth factor and vascular endothelial growth factor receptors in vascular development. Curr. Top. Microbiol. Immunol. 237: 133-158.

Carmeliet, P., V. Ferreira, G. Breier, S. Pollefeyt, L. Kieckens, M Gertsenstein, M. Fahrig, A. Vandenhoeck, K. Harpal, C. Eberhardt, C. Declercq, J. Pawling, L. Moons, D. Collen, W. Risau, and A. Nagy. 1996 Abnormal blood vessel development and lethality in embryos lacking a single VEGF allele. Nature 380: 435-439.

Chen, J., A. Nachabah, C. Scherer, P. Ganju, A. Reith, R. Bronson, and H.E. Ruley. 1996. Germ-line inactivation of the murine Eck receptor tyrosine kinase by gene trap retroviral insertion. Oncogene 12: 979-988.

Daniel, T.O., E. Stein, D.P. Cerretti, P.L. St. John, B. Robert, and D.R. Abrahamson. 1996. ELK and LERK-2 in developing kidney and microvascular endothelial assembly. Kidney Int. Suppl. 57: S73-S81.

Davis, S., N.W. Gale, T.H. Aldrich, P.C. Maisonpierre, V. Lhotak, T. Pawson, M. Goldfarb, and G.D. Yancopoulos. 1994. Ligands for EPH-related receptor tyrosine kinases that require membrane attachment or clustering for activity. Science 266: 816-819.

Davis, S., T.H. Aldrich, P.F. Jones, A. Acheson, D.L. Compton, V. Jain, T.E. Ryan, J. Bruno, C. Radziejewski, P.C. Maisonpierre, and G.D. Yancopoulos. 1996. Isolation of Angiopoietin-1, a ligand for the TIE2 receptor, by secretion-trap expression cloning. Cell 87: 1161-1169.

Dumont, D.J., L. Jussila, J. Taipale, A. Lymboussaki, T. Mustonen, K. Pajusola, M. Breitman, and K. Alitalo. 1998. Cardiovascular failure in mouse embryos deficient in VEGF receptor-3. Science 282: 946-949.

Durbin, L., C. Brennan, K. Shiomi, J. Cooke, A. Barrios, S. Shanmugalingam, B. Guthrie, R. Lindberg, and N. Holder. 1998. Eph signaling is required for segmentation and differentiation of the somites. Genes \& Dev. 12: 3096-3109.

Dvorak, H.F., J.A. Nagy, D. Feng, L.F. Brown, and A.M. Dvorak. 1999. Vascular permeability factor/vascular endothelial growth factor and the significance of microvascular hyperpermeability in angiogenesis. Curr. Top. Microbiol. Immunol. 237: 97-132.

Eph Nomenclature Committee. 1997. Unified nomenclature for Eph family receptors and their ligands, the Ephrins. Cell 90: 403-404.

Eriksson, U. and K. Alitalo. 1999. Structure, expression and receptor-binding properties of novel vascular endothelial growth factors. Curr. Top. Microbiol. Immunol. 237: 41-57.

Ferrara, N. 1999. Vascular endothelial growth factor: Molecular and biological aspects. Curr. Top. Microbiol. Immunol. 237: $1-30$.

Ferrara, N., K. Carver-Moore, H. Chen, M. Dowd, L. Lu, K.S. O'Shea, L. Powell-Braxton, K.J. Hillan, and M.W. Moore. 1996. Heterozygous embryonic lethality induced by targeted inactivation of the VEGF gene. Nature 380: 439-442.

Flanagan, J.G. and P. Vanderhaeghen. 1998. The ephrins and Eph receptors in neural development. Annu. Rev. Neurosci. 21: 309-345.

Flenniken, A.M., N.W. Gale, G.D. Yancopoulos, and D.G. Wilkinson. 1996 Distinct and overlapping expression patterns of ligands for Eph-related receptor tyrosine kinases during mouse embryogenesis. Dev. Biol. 179: 382-401.

Folkman, J. and P.A. D'Amore. 1996. Blood vessel formation: What is its molecular basis? Cell 87: 1153-1155.

Fong, G.H., J. Rossant, M. Gertsenstein, and M.L. Breitman. 
1995. Role of the Flt-1 receptor tyrosine kinase in regulating the assembly of vascular endothelium. Nature 376: 66-70.

Gale, N.W., A. Flenniken, D.C. Compton, N. Jenkins, N.G. Copeland, D.J. Gilbert, S. Davis, D.G. Wilkinson, and G.D. Yancopoulos. 1996a. Elk-L3, a novel transmembrane ligand for the Eph family of receptor tyrosine kinases, expressed in embryonic floor plate, roof plate and hindbrain segments. Oncogene 13: 1343-1352.

Gale, N.W., S.J. Holland, D.M. Valenzuela, A. Flenniken, L. Pan, T.E. Ryan, M. Henkemeyer, K. Strebhardt, H. Hirai, D.G. Wilkinson et al. 1996b. Eph receptors and ligands comprise two major specificity subclasses and are reciprocally compartmentalized during embryogenesis. Neuron 17: 9-19.

Gale, N.W. and G.D. Yancopoulos. 1997. Ephrins and their receptors: A repulsive topic? Cell. Tissue Res. 290: 227-241.

Gassmann, M. and G. Lemke. 1997. Neuregulins and neuregulin receptors in neural development. Curr. Opin. Neurobiol. 7: 87-92.

George, S.E., K. Simokat, J. Hardin, and A.D. Chisholm. 1998. The VAB-1 Eph receptor tyrosine kinase functions in neural and epithelial morphogenesis in C. elegans. Cell 92: 633643.

Hanahan, D. 1997. Signaling vascular morphogenesis and maintenance. Science 277: 48-50.

Hanks, S.K. and A.M. Quinn. 1991. Protein kinase catalytic domain sequence database: Identification of conserved features of primary structure and classification of family members. Methods Enzymol. 200: 38-62.

Henkemeyer, M., D. Orioli, J.T. Henderson, T.M. Saxton, J. Roder, T. Pawson, and R. Klein. 1996. Nuk controls pathfinding of commissural axons in the mammalian central nervous system. Cell 86: 35-46.

Himanen, J.P., M. Hentemeyer, and D.B. Nikolou. 1998. Crystal structure of the ligand-binding domain of the receptor tyrosine kinase EphB2. Nature 396: 486-491.

Hiratsuka, S., O. Minowa, J. Kuno, T. Noda, and M. Shibuya. 1998. Flt-1 lacking the tyrosine kinase domain is sufficient for normal development and angiogenesis in mice. Proc. Nat1. Acad. Sci. 95: 9349-9354.

Hock, B., B. Bohme, T. Karn, T. Yamamoto, K. Kaibuchi, U. Holtrich, S. Holland, T. Pawson, H. Rubsamen-Waigmann, and K. Strebhardt. 1998. PDZ-domain-mediated interaction of the Eph-related receptor tyrosine kinase EphB3 and the ras-binding protein AF6 depends on the kinase activity of the receptor. Proc. Natl. Acad. Sci. 95: 9779-9784.

Holland, S.J., N.W. Gale, G. Mbamalu, G.D. Yancopoulos, M. Henkemeyer, and T. Pawson. 1996. Bidirectional signalling through the EPH-family receptor Nuk and its transmembrane ligands. Nature 383: 722-725.

Holzman, L.B., R.M. Marks, and V.M. Dixit. 1990. A novel immediate-early response gene of endothelium is induced by cytokines and encodes a secreted protein. Mol. Cell. Biol. 10: 5830-5838.

Hsueh, Y.P. and M. Sheng. 1998. Eph receptors, ephrins, and PDZs gather in neuronal synapses. Neuron 21: 1227-1229.

Huynh-Do, U., E. Stein, A.A. Lane, D.P. Cerretti, and T.O. Daniel. 1999. Defined durface densities of Ephrin-B1 determine EphB1-coupled activation of cell attachment through $\alpha \mathrm{v} \beta 3$ and $\alpha 5 \beta 1$ integrins. EMBO T..

Koblizek, T.I., C. Weiss, G.D. Yancopoulos, U. Deutsch, and W. Risau. 1998. Angiopoietin-1 induces sprouting angiogenesis in vitro. Curr. Biol. 8: 529-532.

Kramer, R., N. Bucay, D.J. Kane, L.E. Martin, J.E. Tarpley, and L.E. Theill. 1996. Neuregulins with an Ig-like domain are essential for mouse myocardial and neuronal development. Proc. Nat1. Acad. Sci. 93: 4833-4838.
Krull, C.E., R. Lansford, N.W. Gale, A. Collazo, C. Marcelle, G.D. Yancopoulos, S.E. Fraser, and M. Bronner-Fraser. 1997. Interactions of Eph-related receptors and ligands confer rostrocaudal pattern to trunk neural crest migration. Curr. Biol. 7: 571-580.

Kukk, E., A. Lymboussaki, S. Taira, A. Kaipainen, M. Jeltsch, V. Joukov, and K. Alitalo. 1996. VEGF-C receptor binding and pattern of expression with VEGFR-3 suggests a role in lymphatic vascular development. Development 122: 3829-3837.

Lee, K.F., H. Simon, H. Chen, B. Bates, M.C. Hung, and C. Hauser. 1995. Requirement for neuregulin receptor erbB2 in neural and cardiac development. Nature 378: 394-398.

Lin, D., G.D. Gish, Z. Songyang, and T. Pawson. 1999. The carboxyl terminus of B class ephrins constitutes a PDZ domain binding motif. J. Biol. Chem. 274: 3726-3733.

Lindahl, P., B.R. Johansson, P. Leveen, and C. Betsholtz. 1997. Pericyte loss and microaneurysm formation in PDGF-B-deficient mice. Science 277: 242-245.

Maisonpierre, P.C., C. Suri, P.F. Jones, S. Bartunkova, S.J. Wiegand, C. Radziejewski, D. Compton, J. McClain, T.H. Aldrich, N. Papadopoulos, et al. 1997. Angiopoietin-2, a natural antagonist for Tie2 that disrupts in vivo angiogenesis. Science 277: 55-60.

McBride, J.L. and J.C. Ruiz. 1998. Ephrin-A1 is expressed at sites of vascular development in the mouse. Mech. Dev. 77: 201204.

Meyer, D. and C. Birchmeier. 1995 Multiple essential functions of neuregulin in development. Nature 378: 386-390.

Neufeld, G., T. Cohen, S. Gengrinovitch, and Z. Poltorak. 1999. Vascular endothelial growth factor (VEGF) and its receptors. FASEB T. 13: 9-22.

O'Leary, D.D.M., P.A. Yates, and T. McLaughlin. 1999. Molecular development of sensory maps: Representing sights and smells in the brain. Cell 96: 255-269.

Orioli, D., M. Henkemeyer, G. Lemke, R. Klein, and T. Pawson. 1996. Sek 4 and Nuk receptors cooperate in guidance of commissural axons and in palate formation. EMBO J. 15: 60356049.

Pandey, A., H. Shao, R.M. Marks, P.J. Polverini, and V.M. Dixit. 1995. Role of B61, the ligand for the Eck receptor tyrosine kinase, in TNF-alpha induced angiogenesis. Science 268: 567-569.

Park, S., J. Frisen, and M. Barbacid. 1997. Aberrant axonal projections in mice lacking EphA8 (Eek) tyrosine protein kinase receptors. EMBO J. 16: 3106-3114.

Risau, W. 1997. Mechanisms of angiogenesis. Nature 386: 671674.

Robinson, V., A. Smith, A.M. Flenniken, and D.G. Wilkinson. 1997. Roles of Eph receptors and ephrins in neural crest pathfinding. Cell. Tissue Res. 290: 265-274.

Sakano, S., R. Serizawa, T. Inada, A. Iwama, A. Itoh, C. Kato, Y. Shimizu, F. Shinkai, R. Shimizu, S. Kondo, et al.. 1996. Characterization of a ligand for receptor protein-tyrosine kinase HTK expressed in immature hematopoietic cells. Oncogene 13: $813-822$.

Sato, T.N., Y. Tozawa, U. Deutsch, K. Wolburg-Buchholz, Y. Fujiwara, M. Gendron-Maguire, T. Gridley, H. Wolburg, W. Risau, and Y. Qin. 1995. Distinct roles of the receptor tyrosine kinases Tie-1 and Tie-2 in blood vessel formation. Nature 376: 70-74.

Schultz, J., C.P. Ponting, K. Hofmann, and P. Bork. 1997. SAM as a protein interaction domain involved in developmental regulation. Protein Sci. 6: 249-253.

Shalaby, F., J. Rossant, T.P. Yamaguchi, M. Gertsenstein, X.F. Wu, M.L. Breitman, and A.C. Schuh. 1995. Failure of bloodisland formation and vasculogenesis in Flk-1-deficient mice. 
Nature 376: 62-66.

Shalaby F., J. Ho, W.L. Stanford, K.D. Fischer, A.C. Schuh, L. Schwartz, A. Bernstein, and J. Rossant. 1997. A requirement for FIKI in primitive and definitive hematopoiesis and vasculogenesis. Cell 89: 981-990.

Smith, A., Robinson, K. Patel, and D.G. Wilkinson. 1997. The EphA4 and EphB1 receptor tyrosine kinases and ephrin-B2 ligand regulate targeted migration of branchial neural crest cells. Curr. Biol. 1: 561-570.

Stapleton, D., I. Balan, T. Pawson, and F. Sicheri. 1999. The crystal structure of an Eph receptor SAM domain reveals a mechanism for modular dimerization. Nat. Struct. Biol. 6: 44-49.

Stein, E., U. Huynh-Do, A.A. Lane, D.P. Cerretti, and T.O. Daniel. 1998a. Nck recruitment to Eph receptor, EphB1/ ELK, couples ligand activation to c-Jun kinase. J. Biol. Chem. 273: 1303-1308

Stein, E., A.A. Lane, D.P. Cerretti, H.O. Schoecklmann, A.D. Schroff, R.L. Van Etten, and T.O. Daniel. 1998b. Eph receptors discriminate specific ligand oligomers to determine alternative signaling complexes, attachment, and assembly responses. Genes \& Dev. 12: 667-678.

Suri, C., P.F. Jones, S. Patan, S. Bartunkova, P.C. Maisonpierre, S. Davis, T.N. Sato, and G.D. Yancopoulos. 1996. Requisite role of Angiopoietin-1, a ligand for the TIE2 receptor, during embryonic angiogenesis. Cell 87: 1171-1180.

Suri, C., J. McClain, G. Thurston, D.M. McDonald, H. Zhou, E.H. Oldmixon, T.N. Sato, and G.D. Yancopoulos. 1998. Increased vascularization in mice overexpressing Angiopoietin-1. Science 282: 468-471.

Thanos, C.D., K.E. Goodwill, and J.U. Bowie. 1999. Oligomeric structure of the human EphB2 receptor SAM domain. Science 283: 833-836.

Thurston, G., P. Baluk, A. Hirata, and D.M. McDonald. 1996. Permeability-related changes revealed at endothelial cell borders in inflamed venules by lectin binding. Am. J. Physiol. 271: H2547-H2562.

Torres, R., B.L. Firestein, H. Dong, J. Staudinger, E.N. Olson, R.L. Huganir, D.S. Bredt, N.M. Gale, and G.D. Yancopoulos. 1998. PDZ proteins bind, cluster, and synaptically colocalize with Eph receptors and their ephrin ligands. Neuron 21: 1453-1463.

Valenzuela, D.M., J.A. Griffiths, J. Rojas, T.H. Aldrich, P.F. Jones, H. Zhou, J. McClain, N.G. Copeland, D.J. Gilbert, N.A. Jenkins, et al. 1999. Angiopoietins 3 and 4: Diverging gene counterparts in mice and humans. Proc. Natl. Acad. Sci. 96: 1904-1909.

Wang, H.U. and D.J. Anderson. 1997. Eph family transmembrane ligands can mediate repulsive guidance of trunk neural crest migration and motor axon outgrowth. Neuron 18: 383 396.

Wang, H.U., Z.F. Chen, and D.J. Anderson. 1998. Molecular distinction and angiogenic interaction between embryonic arteries and veins revealed by ephrin-B2 and its receptor Eph-B4. Cell 93: 741-753.

Winslow, J.W., P. Moran, J. Valverde, A. Shih, J.Q. Yuan, S.C. Wong, S.P. Tsai, A. Goddard, W.J. Henzel, F. Hefti et al. 1995. Cloning of AL-1, a ligand for an Eph-related tyrosine kinase receptor involved in axon bundle formation. Neuron 14: 973-981.

Xu, Q., G. Alldus, N. Holder, and D.G. Wilkinson. 1995. Expression of truncated Sek-1 receptor tyrosine kinase disrupts the segmental restriction of gene expression in the Xenopus and zebrafish hindbrain. Development 121: 4005-4016.

$\mathrm{Xu}$, Q., G. Alldus, R. Macdonald, D.G. Wilkinson, and N. Holder. 1996. Function of the Eph-related kinase rtk1 in pat- terning of the zebrafish forebrain. Nature 381: 319-322.

Yancopoulos, G.D., M. Klagsburn, and J. Folkman. 1998. Vasculogenesis, angiogenesis, and growth factors: Ephrins enter the fray at the border. Cell 93: 661-664.

Zhao, J.J. and G. Lemke. 1998. Selective disruption of neuregulin-1 function in vertebrate embryos using ribozyme-tRNA transgenes. Development 125: 1899-1907.- 


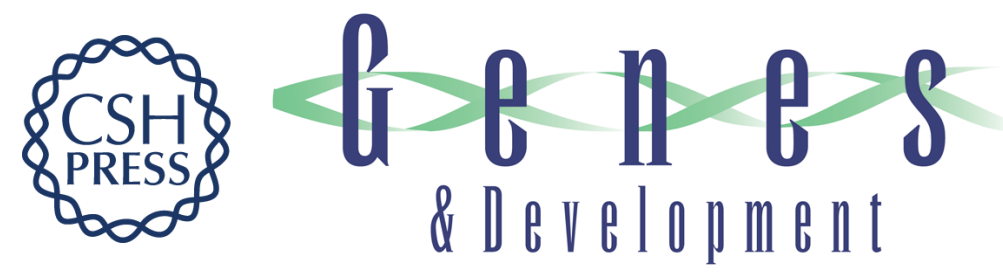

\section{Growth factors acting via endothelial cell-specific receptor tyrosine kinases: VEGFs, Angiopoietins, and ephrins in vascular development}

Nicholas W. Gale and George D. Yancopoulos

Genes Dev. 1999, 13:

References This article cites 74 articles, 22 of which can be accessed free at:

http://genesdev.cshlp.org/content/13/9/1055.full.html\#ref-list-1

License

Email Alerting

Receive free email alerts when new articles cite this article - sign up in the box at the top

Service

right corner of the article or click here.

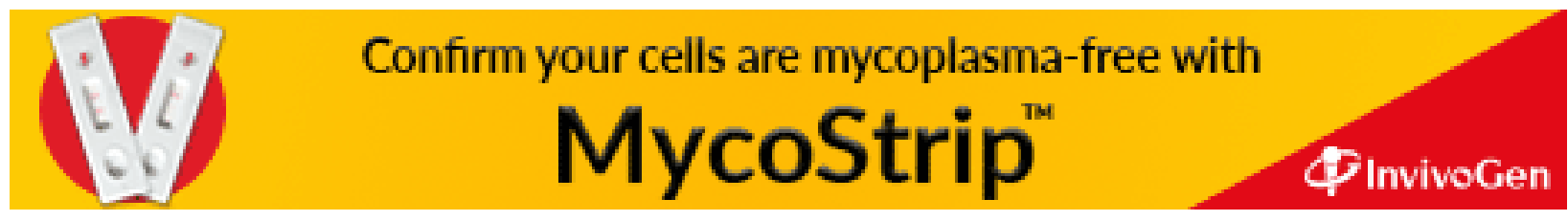

